\title{
BIRTH ORDER IN EPILEPTIC CHILDREN
}

\author{
T. COLVER AND D. F. KERRIDGE \\ From the Sheffield Children's Hospital and the Department of Statistics, \\ University of Sheffield
}

A knowledge of birth order can be contributory to the evaluation of hereditary and environmental factors in disease. There is, however, no agreement as to whether a characteristic birth order pattern exists in epilepsy. Thus Brain (1956) and Lennox (1960) have written respectively 'epilepsy is relatively commoner among first born children than among later members of the family' and 'birth order is uninfluential'. In view of this contradictory situation, we have re-examined the question in respect of first and second births.

\section{PREVIOUS REPORTS ON BIRTH ORDER IN EPILEPSY}

Brain (1926) compared the birth order of 210 epileptics with that of 876 hospital patients and found the epileptics both first and second born significantly more often than the controls, but Green (1928) found the birth order distribution of 1,000 epileptics showed no special features. Nielsen and Butler (1947), publishing summarized data, reported that $39.2 \%$ of 956 epileptics were first born, the average number of sibs in each family being $4 \cdot 1$. Bridge (1949) compared the actual and expected birth order distribution of 568 epileptic children and concluded that there was no significant difference, and Alström (1950), investigating 897 epileptics, learned the numbers of sibs in each family, grouped together the families of equal size, noted the birth order position of the epileptics in each group, and concluded that these showed no special features. He emphasized that numbers of epileptics with symptoms beginning in childhood may have been excluded owing to prior transfer to residential institutions. Orr and Risch (1953), investigating 153 epileptics, arranged their clinical material similarly but came to a different conclusion, namely, that the epileptics were born more often than expected towards the end of large families. They emphasized, however, that their numbers were small.

Though the above results seem conflicting, it is doubtful if they are comparable. Thus ages of onset were not recorded in those studies which included attacks in infancy and childhood, and it was not clear what steps were taken to exclude examples of simple febrile convulsions. Though it is not possible to distinguish all examples of simple febrile convulsions from all examples of chronic epilepsy, differentiation must be attempted and defined for results to be comparable. Enquiries of the type conducted by Brain and Bridge are valuable to the extent that the control material is adequate in respect of such inter-related factors as family size, area of habitation, economic position, race, religion, and frequency of epilepsy in the particular community. The latter factors were controlled by Alström (1950) and Orr and Risch (1953) by their use of sibs of the reference epileptics as controls but here bias was possible to the extent that parents who have had an epileptic child might limit family size afterwards, causing such an epileptic to hold a relatively late birth order position in the family.

\section{METHOD OF ENQUIRY}

With all these considerations in mind, the following method of enquiry was adopted. From the hospital records all patients diagnosed as epileptics (1947-54) were collected and follow-up enquiries on them conducted during 1957 and 1961. There were then selected for further investigation those who were either first born with a second born sib control, or second born with a first born sib control, and had suffered 10 or more 'convulsion days', a 'convulsion day' being defined as any day in which the patient had one or more convulsions. The first stipulation secured the advantages of Alströ.n's enquiry but placed bias on the epileptics of the enquiry series being second rather than first born, and the second stipulation excluded convulsions which were exclusively febrile and also slight, infrequent convulsions, so minimizing bias which might arise from the possible tendency of parents to be more worried by illnesses in first children, that is, the standard of severity adopted was such that the affected children were likely to have been referred for hospital investigation whatever their birth order. It remained to arrange that the sibs of each pair be observed for 
the same length of time from birth. For this purpose, the 'longest common life observation period' was used. In one pair, for instance, one sib was 4 years old when convulsions started, and 5 years old at the time of the follow-up enquiry, but the other died at 3 years of age. The longest common life observation period of such a pair would be three years and no convulsions therefore occurred during the period of this pair, which was therefore ineligible for the final enquiry series. This use of the longest common life observation period did in fact put further bias on the epileptics of the enquiry series being second born. There were finally excluded those two pairs in which both reference patient and sib control presented 10 or more 'convulsion days' during the longest common life observation period. To sum up, the known factors which might cause bias were either eliminated or made to favour the second born. Any significant excess of first borns still found among the epileptics of the enquiry series would thus constitute evidence of there being a characteristic birth order pattern in epilepsy.

The 906 epileptics on the diagnostic index cards for the years 1947-54 had been indexed under the headings epilepsy, convulsions, fever convulsions, grand mal, infantile spasms, petit mal, pyknolepsy, status epilepticus, and Jacksonian epilepsy. When, as from 1950, the hospital used the sixth revision of the international list of diseases, the above conditions were found under the numbers $353.0,353 \cdot 1,353 \cdot 2$, $353 \cdot 3,780 \cdot 2$, and $780 \cdot 3$. No patients were found indexed under the remaining 13 numbers applicable to various convulsive states. Enquiries into dates of births of sibs and stillbirths, into progress, and into the frequency and nature of any convulsions in sibs were made during 1957-61. The information was obtained from hospital records, parents, family doctors, local authorities, executive councils, and other institutions, and we are obliged to Professor R. S. Illingworth for the opportunity to include patients of his in the enquiry. In accordance with the method described, there were now excluded from the original 906 patients those in whom birth order could not be learned and those (all single, third born, and later born children) who did not conform to the sib pair pattern described. At this stage, there remained 348 sib pairs from which there were now excluded 156 pairs in which neither the reference patient nor the sib control was known to have suffered 10 convulsion days, 16 pairs in which neither reference patient nor sib control was known to have suffered 10 convulsion days during the longest common life observation period, and two pairs in which both sibs suffered 10 or more convulsion days during that period. There thus remained in the final enquiry series 174 pairs, each comprising the reference patient and his sib control.

\section{RESULTS}

Among the 174 reference epileptics of the final series, 106 were first born against 68 second born, this difference being significant at the 1 in 100 level (Table). After classifying the patients according to the age at onset of convulsions, it was found that among 84 with symptoms beginning in the first two years of life 56 were first born against 28 second born and this difference is significant at the 1 in 200 level. (It must be observed that the sib pair method and the use of the longest common life observation period probably contributed to the apparent decline with age of onset in the ratio between first and second born.)

Numbers were insufficient to indicate if the predominance of first births was significantly greater when symptoms began in the first rather than the second year of life or the earlier rather than the later half of the first year; the nature of any correlation between duration of epilepsy and birth order; the nature of any correlation between type of epilepsy and birth order. In respect of the last point the inherent difficulties of classification were aggravated by the fact that the patients had been investigated by various physicians (sometimes many years ago), that clinical as opposed to correspondence follow-ups have not all been completed, and that comprehensive electroencephalography has not always been available. The attacks of 21 were, however, taken as central in origin and those of $\mathbf{4 5}$ as focal in origin (including temporal lobe epilepsy), while, in the face of inadequate or conflicting findings, the attacks of 108 were undifferentiated in respect of origin. The

TABLE

BIRTH ORDER OF 174 EPILEPTIC CHILDREN

\begin{tabular}{|c|c|c|c|c|c|c|c|c|c|c|c|c|c|c|}
\hline Age of onset & Under 1 & 1 & 2 & 3 & 4 & 5 & 6 & 7 & 8 & 9 & 10 & 11 & 12 & All ages \\
\hline Totals & 58 & 26 & 8 & 15 & 14 & 9 & 7 & 7 & 7 & 9 & 5 & 5 & 4 & 174 \\
\hline $\begin{array}{l}\text { Birth order } \\
\text { First born }\end{array}$ & 37 & 19 & 5 & 5 & 8 & 6 & 5 & 5 & 5 & 4 & 3 & 2 & 2 & 106 \\
\hline Second born & 21 & 7 & 3 & 10 & 6 & 3 & 2 & 2 & 2 & 5 & 2 & 3 & 2 & 68 \\
\hline
\end{tabular}


ratios of first to second births in these three groups were $13: 8,27: 18$, and $69: 39$ respectively and the incidence of 'grand mal', 'grand mal + petit mal', 'petit mal', and 'other' attacks was $(5,10,6,0)$, $(26,3,1,15)$, and $(94,5,5,4)$ respectively.

\section{THE EXCLUDED PAIRS}

One hundred and fifty-six pairs were excluded on the grounds (for reasons described above) that the reference patient had suffered fewer than 10 convulsion days by the time of the last follow-up enquiry. The first born-second born ratio among these excluded patients is $68: 88$ and it is believed that this excess of second born is attributable to those patients whose attacks are of the simple febrile type, i.e., to patients whose exclusion does not bias the result of the main enquiry into the birth order of chronic epileptics. The reasons for this belief do, however, require amplification.

The excluded pairs fall into two groups. Group 1 comprises 71 patients with afebrile attacks (with or without initial febrile attacks) and a birth order ratio of $46: 25$. Group 2 comprises 85 patients with febrile attacks only and a birth order ratio of $22: 63$. Presumably the first-born sib brings home school infections to affect the younger sib in the pre-school period when febrile convulsions are likelier (Brimblecombe, Cruickshank, Masters, and Reid, 1958). Group 2 can be further divided into two subgroups $2 \mathrm{a}$ and $2 \mathrm{~b}$. Subgroup $2 \mathrm{a}$ contains only patients with convulsions of the simple febrile type not therefore destined to develop later afebrile attacks. Subgroup 2b contains only patients whose attacks (as yet febrile only) are destined later to be afebrile. Though the total number in group 2 is 85 , the numbers in each of the subgroups are clearly not known precisely. There are reasons for believing, however, that the size of subgroup $2 b$ is substantially smaller than that of subgroup $2 \mathrm{a}$ and that it amounts to no more than one-fifth of group 2, for long-term follow-up studies (Livingston, 1958) have indicated that approximately half the patients initially referred to a children's hospital on account of febrile convulsions subsequently developed afebrile attacks. Our group 2 patients are, however, differently selected from such a group as Livingston's, because during the hospital follow-up periods described, any of our patients whose initial febrile attacks gave place to afebrile attacks were abstracted from group 2 and allocated to group 1 . This progressive selection leaves in group 2 therefore a higher proportion of patients with simple febrile convulsions than would otherwise have been the case, and some indication of the extent of this selection is given by certain figures of Lennox (1953) which suggest that when afebrile attacks succeed febrile ones they usually do so within two years.

Certain clinical features among our group 2 patients are also compatible with the great majority being of the simple febrile type, i.e., the convulsionfree, drug-free portions of the follow-up periods among our group 2 patients were 10 years (three cases), nine years (four cases), eight years (nine cases), seven years (13 cases), six years (10 cases), five years (six cases), four years (nine cases), three years (10 cases), two years (two cases), one year (four cases), six to 11 months (six cases), and less than six months (nine cases). The ages of onset were less than one year in 30 patients, one year in 29 patients, two years in 10 patients, three years in six patients, four years in four patients, five years in five patients, and six years in one patient. The number of convulsion days suffered were one in 38 patients, two in 19 patients, three in 14 patients, four in eight patients, five in two patients, and six in four patients. Consequently we have concluded that the size of the subgroup $2 b$ is less than a fifth of that of group 2. For calculation purposes, however, its size can be taken as one-fifth of group 2 , i.e., 17 patients $(85 \div 5)$ with a birth order ratio of $4: 13$, assuming the same ratio has already been seen for group 2 as a whole. To sum up, the patients among these excluded pairs with afebrile attacks (group 1) or destined to suffer later afebrile attacks (subgroup 2b) number 71 and 17 respectively (total $=88$ ) and the birth order ratios are 46:25 and 4:13 respectively (aggregate $=50: 38$ ). It seems improbable, therefore, that these exclusions have seriously biased the final conclusions of this report in respect of the birth order pattern among chronic epileptics.

\section{DISCUSSION}

Of the other reports based on adequate numbers, those of Brain (1926), Green (1928), and Alström (1950) record no undue predominance of first over second births among epileptics. That of Bridge does, however, on our own calculations from his figures, show such a predominance, and it is of interest that his is the only one which like our own dealt exclusively with children. There is the possibility therefore that the predominance of first over second births is more marked among epileptics whose symptoms had begun in infancy and childhood.

Whether the predominance of first births among our patients implies a risk attaching to first births as such or a risk attaching to low maternal age is not known. Beall and Stanton (1946) found 'a general indication that the probability of epilepsy increases with extremely high maternal age and possibly with very low' but they did not take birth order into 
account. The maternal ages of the 106 first born reference patients of our final series were under 20 years, over 20 years, over 25 years, over 30 years, over 35 years, and of unknown age in 13, 45, 26, six, two, and 14 women respectively but comparison of these ages with those for first born children in the country at large (the Registrar General's Statistical Review of England and Wales for 1947 and 1958) gives no clear indication as to whether our series includes an undue proportion of very young mothers.

Among other conditions presenting a predominance of first over second births, there is perinatal death (stillbirths and deaths in the first week of life). This familiar fact was reflected in the broad figures of Baird, Walker, and Thompson (1954) and when these authors differentiated the deaths as far as possible according to causation, it was also found that in each of the four largest ('mature, cause unknown', 'trauma and stress asphyxia', 'premature, cause unknown', and 'deformity') of their seven cause groups, the same trend persisted. Deaths during the first week of life, stillbirths, and epilepsy as defined may in fact have important causes in common.

\section{CONCLUSIONS}

It has been established beyond reasonable doubt that epilepsy as defined above is more frequent in first than in second born children. The problem of the significance of this difference is complex and quite beyond the scope of this enquiry. The results, however, taken with the similar birth order differences among stillbirths and deaths in the first week of life, are at least consistent with the hypothesis that these occurrences and epilepsy in childhood may have important causes in common.

We thank Mrs. M. E. Stirland for the documentation. The Endowment Fund of the United Sheffield Hospitals defrayed expenses.

\section{REFERENCES}

Alström, C. H. (1950). Acta psychiat (Kbh.), Suppl. 63.

Baird, D., Walker, J., and Thompson, A. M. (1954). J. Obstet. Gynec. Brit. Cwlth, Vol. 61, (n.s.) p. 433.

Beall, G., and Stanton, R. G. (1946). Hum. Biol., 18, 49.

Brain, Russell (1926). Quart. J. Med., 19, 299.

- (1956). Diseases of the Nervous System, 5th ed., p. 987. Oxford University Press, London.

Bridge, E. N. (1949). Epilepsy and Convulsive Disorders in Childhood. McGraw-Hill, New York and London.

Brimblecombe, F. S. W., Cruickshank, R., Masters, P. L., and Reid, D. D. (1958). Brit. med. J., 1, 119.

Green, W. (1928). J. Mich. med. Soc., 27, 5, 25.

Lennox, W. G. (1953). Pediatrics, 11, 341.

- (1960). Textbook of Medicine, 10th ed., p. 1426. Cecil and Loeb. W. B. Saunders, Philadelphia and London.

Livingston, S. (1958). Advanc. Pediat., 10, 118.

Nielsen, J. M., and Butler, F. O. (1947). Trans. Amer. neurol. Ass. $72,201$.

Orr, J. K., and Risch, F. (1953). Neurology, 3, 679. 